\title{
O NEGRO EM Ó, PAÍ, Ó: CINEMA, CORPO E DISCURSO.
}

\section{THE BLACK PEOPLE IN Ó, PAÍ, Ó: MOVIES, BODY AND DISCOURSE.}

\author{
Luisa da Silva Hidalgo* \\ Luciana Iost Vinhas**
}

RESUMO: Primeiramente, a Análise de Discurso, teoria fundamentada pelo filósofo Michel Pêcheux, na França, ocupava-se em trabalhar sobre o discurso político. Com o passar do tempo, outras materialidades passaram a figurar nos estudos do discurso, como, por exemplo, textos verbais escritos, textos verbais orais, imagens, corpo e obras cinematográficas (filmes), entre outras. O corpus que constituirá nosso trabalho advém de um filme intitulado Ó Paí, Ó (2007). O referido filme foi produzido no Brasil, mais precisamente no estado da Bahia. O filme, em um primeiro momento, parece se enquadrar no gênero Comédia, porém, um olhar mais atento à obra revela questões mais profundas, como o racismo e o genocídio do negro no Brasil. O objetivo principal de nosso artigo é refletir sobre as questões do racismo e suas implicações no corpo negro a partir de algumas sequências discursivas presentes em um diálogo entre duas personagens do filme Ó Paí, Ó. Para tanto, utilizaremos alguns dos conceitos mobilizados pela Análise de Discurso, como memória, formações imaginárias e condições de produção dos discursos. Com a análise, conseguimos trazer elementos que apontam para a possibilidade de resistência frente a saberes hegemônicos sobre a negritude, o que acontece a partir da observação das formulações das personagens Boca e Roque na narrativa filmica em questão.

ABSTRACT: First of all, Discourse Analysis, a theory developed by the philosopher Michel Pêcheux, in France, aimed to work with the political discourse. In the course of time, other materialities were found in the discourse studies, as, for instance, written verbal texts, oral verbal texts, images, body, and movies, among others. This paper has a corpus from the movie Ó Paí, Ó (2007). This movie was produced in Brazil, more precisely in the State of Bahia. Initially, the movie seems to be characterized as a Comedy genre, however, a closer look reveals deeper questions, for example, racism and the black people genocide in Brazil. The main purpose of this paper is to reflect about questions related to racism and their implications on black people bodies, based in some discursive sequences from a dialogue between two characters of the movie Ó Paí, Ó. For this purpose, we use some concepts from the Discourse Analysis: memory, imaginary formations and production conditions of the discourses. With the analysis, we managed to bring out elements that point to the possibility of resistance against the hegemonic knowledge about blackness, which happens from the observation of the formulations of the characters Boca and Roque in the filmic narrative in question.

PALAVRAS-CHAVE: Ó Paí, Ó; Racismo; Discurso.

KEYWORDS: Ó Paí, Ó; Racism; Discourse.

\section{INTRODUÇÃO}

O embasamento teórico que sustenta o presente trabalho concerne aos pressupostos desenvolvidos pelo filósofo Michel Pêcheux na França, no final da década de 1960. No início dos estudos nesse campo, as pesquisas preocupavam-se em analisar corpora

INTERLETRAS, ISSN N $N^{\circ}$ 1807-1597. V. 9, Edição número 34. Outubro, 2021/ Março de 2022- p.

Dossiê: Estudos de indigenismo, negritude e miscigenação: o (des)cobrimento, colonização e o agora(?). 
oriundos do discurso político cuja base era linguística, considerando que, para Pêcheux, a forma material da ideologia era, por excelência, a língua. No entanto, com o passar do tempo, diferentes formas materiais passaram a figurar nos estudos do discurso. Tem-se, atualmente, trabalhos que se baseiam em materialidades verbais e não-verbais, como, por exemplo, postagens em redes sociais na internet, o corpo, obras cinematográficas (filmes), entre outras.

A materialidade discursiva que constituirá o corpus de nosso trabalho advém de uma obra cinematográfica. Entendemos o cinema como uma forma artística da qual emergem diferentes efeitos de sentido entre interlocutores (PÊCHEUX, [1969] 1997), ou seja, a partir dele diferentes discursos podem ser colocados em circulação. Privilegiaremos, em nosso trabalho, uma obra cinematográfica produzida no Brasil, mais precisamente no estado da Bahia, intitulada Ó Paí, Ó (2007). Com isso, será possível desenvolver uma reflexão que articula corpo e negritude pela análise do funcionamento discursivo na obra citada.

Ó Paí, Ó (2007) é um filme de longa-metragem brasileiro dirigido e adaptado para o cinema pela cineasta Monique Gardenberg a partir de uma peça teatral escrita por Márcio Meirelles, em 1992, para o Bando de Teatro Olodum. O filme narra a história de alguns moradores da periferia de Salvador (BA), nas proximidades do Pelourinho, durante o Carnaval, importante símbolo cultural do Brasil e do estado da Bahia. O enredo traz como cenário principal um cortiço, de cuja dona, uma caricata evangélica chamada Dona Joana, decide cortar a água no último dia de Carnaval como forma de retaliação pela algazarra dos condôminos.

No filme $O$ Paí, $O$ desenvolvem-se tramas paralelas cômicas e divertidas, ao som de muito Axé. Superficialmente, o filme mostra um imaginário estereotipado do baiano já conhecido por muitos brasileiros: o baiano alegre, descontraído, dançante e amante do Carnaval. Porém, um olhar mais atento ao filme revela questões mais profundas, como o discurso racista incutido em uma sociedade majoritariamente negra e a visibilidade do corpo negro em destaque no cinema, já que o elenco é predominantemente negro.

Este olhar atento e também questionador sobre $O$ Paí, $O$ levou-nos a pensar nas questões de cor/raça negra presentes no filme, pelo viés da Análise de Discurso (AD), teoria que busca relacionar a linguagem à sua exterioridade (ORLANDI, 2005). A AD passa a considerar no enunciado o sujeito e o sentido. Entendendo que sem sujeito não há discurso, o sujeito inscrito na história e duplamente afetado pelo inconsciente e pela ideologia é peça fundamental na análise que pretendemos desenvolver. É partir da noção de sujeito que chegaremos à noção de corpo em Análise de Discurso, fundamental para pensar em questões de negritude reproduzidas pelo filme.

O objetivo principal de nosso artigo é refletir sobre as questões do racismo e suas implicações no corpo negro a partir de algumas Sequências Discursivas (SD) presentes em um diálogo entre duas personagens do filme $O$ Paí, Ó. Para tanto, utilizaremos alguns

INTERLETRAS, ISSN N $N^{\circ}$ 1807-1597. V. 9, Edição número 34. Outubro, 2021/ Março de 2022- p.

Dossiê: Estudos de indigenismo, negritude e miscigenação: o (des)cobrimento, colonização e o agora(?) . 
dos conceitos mobilizados pela $\mathrm{AD}$, como a memória, as formações imaginárias e as condições de produção do discurso.

\section{SOBRE O CORPO (NEGRO) E O RACISMO}

De acordo com Souza (2010, p. 01), só há sujeito em um corpo. Desta forma, o ele é parte fundamental para aprofundarmos as questões de discursos que envolvem, principalmente, o corpo negro, o marcado corpo negro, o qual é objeto de interpretação: ele significa como o corpo subalternizado, marginalizado; é não-hegemônico em uma sociedade que reproduz o discurso racista. Sem nenhuma palavra proferida, ele fala e materializa a resistência de um povo escravizado e humilhado, que resiste.

O Brasil é majoritariamente um país negro. De acordo com o IBGE, em pesquisa divulgada em 2016, somando as cores "preta" e "parda", mais de 50\% da população é negra. Este número remete às pessoas autodeclaradas, por isso podemos supor que o número possa variar, já que muitas pessoas negam a cor negra e, por conseguinte, se autodeclaram brancas (por não se identificarem com o imaginário de "pessoa negra" construído na nossa formação social).

Considerando a não transparência da língua, o fato de as categorias do IBGE sobre raça/cor serem branca, preta e parda demonstra o quanto o processo de branqueamento afeta os sentidos sobre raça na população brasileira. Quando ocorre a bipartição entre "preta" e "parda" de uma população que em sua maioria é negra, a questão do racismo e da forma como ele atua na sociedade fica latente. Segundo pesquisa do IBGE (2016), $8,2 \%$ dos brasileiros se autodeclaram pretos e $46,7 \%$ pardos $^{1}$. Por que não se autodeclarar preto? Por que não unificar em uma única categoria de "negros"? Diante desses questionamentos, pensamos na memória que se constituiu sobre o negro brasileiro desde a escravidão aos dias de hoje. A negação da negritude não existe por acaso. Inúmeras questões históricas, sociais e ideológicas permeiam essa negação.

A marginalização, a subserviência e a repressão da classe dominante branca marcam a história do negro no Brasil e reforçam a negação deste corpo negro. A complexidade e dificuldade de querer ser e se querer negro é grande, conforme as palavras de Jurandir Freire Costa no prefácio de "Tornar-se negro", de Neusa Souza:

Ser negro é ser violentado de forma constante, contínua e cruel, sem pausa ou repouso, por uma dupla injunção: a de encarnar o corpo e os ideais do Ego do sujeito branco e a de recusar, negar e anular a presença do corpo negro (COSTA, 1983, p. 02).

1 Dados disponíveis em: <https://agenciadenoticias.ibge.gov.br/agencia-noticias/2012-agencia-denoticias/noticias/18282-populacao-chega-a-205-5-milhoes-com-menos-brancos-e-mais-pardos-epretos $>$ Acesso em 10 de ago. de 2019.

INTERLETRAS, ISSN N 1807-1597. V. 9, Edição número 34. Outubro, 2021/ Março de 2022- p.

Dossiê: Estudos de indigenismo, negritude e miscigenação: o (des)cobrimento, colonização e o agora(?) . 
A negação do corpo negro é compreensível, em uma sociedade em que os negros, ainda que ascendendo socialmente, permanecem dominados por uma ideologia branca, a qual determina o imaginário do negro sobre si mesmo. O corpo negro, marcado com o ferro em brasa, assim como gado, no período da escravidão, segue marcado, não por um ferro em brasa, mas violentado pela dominância da ideologia branca. Esse corpo, ainda marcado, resiste.

Ainda para Costa (1983, p. 04 [grifos do autor]), o ego seria:

Produto formado a partir de imagens e palavras, representações e afetos que circulam incessantemente entre a criança e o adulto, entre o sujeito e a cultura. Sua função no caso ideal é a de favorecer o surgimento de uma identidade do sujeito, compatível com o investimento erótico de seu corpo e de seu pensamento, via indispensável a sua relação harmoniosa com os outros e com o mundo. [...] Ao sujeito negro, esta possibilidade é, em grande parte, sonegada. O modelo de Ideal de Ego oferecido em troca da antiga aspiração narcísico-imaginária não é um modelo humano de existência psíquica concreta, histórica e, consequentemente, realizável ou atingível. O modelo de identificação normativo-estruturante com o qual ele se defronta é o de um fetiche: o fetiche do branco, da brancura.

Conforme aponta o autor, a função ideal do Ego é a de favorecer o surgimento de uma identidade do sujeito. Em relação ao corpo negro, o modelo de Ego oferecido pela sociedade é o do Ego branco, e este modelo é o que "favorece" o surgimento da "identidade" do sujeito negro, ou seja, o negro constrói a sua "identidade" de sujeito baseado em um Ego branco. Dessa forma, o sujeito negro não deseja um Ego negro, pois o modelo de identificação oferecido ao negro é o fetiche da brancura. Vivemos em uma sociedade em que a negritude não compõe objeto de fetiche. A negritude é feia, é pobre, é suja, é inferior. Quando fetichizada, passa por uma romantização da imagem do corpo negro. Já a brancura é bela, é superior, é pura, é nobre. Sendo assim, compreendendo a teorização a partir do conceito de formações imaginárias ${ }^{2}$, podemos afirmar que o processo de se tornar sujeito é atravessado por determinações ideológicas que constituem a forma como o sujeito se representa socialmente, e essa representação de si, ou seja, o imaginário de si, é atravessado pelo ideal de branquitude como ideologia dominante na nossa formação social.

Pensando na questão do corpo como discurso, Souza (2010) diz que a carne passa a corpo em um processo chamado de discursivização da carne, uma vez que um corpo não atravessado pelo discurso é somente carne, conforme previsto na teoria psicanalítica, base do trabalho do autor. Souza (2010) aponta ainda que, neste processo de discursivização, ocorre um trabalho realizado pelos agentes ideológicos que cuidam de imaginá-la, esperála, erguê-la, educá-la, administrá-la, alocá-la em corpodiscurso. Em outras palavras, como

\footnotetext{
2 Tomamos as formações imaginárias conforme o desenvolvimento teórico de Pêcheux (2019): “(...) o que funciona nos processos discursivos é o lugar que A e B se atribuem cada um a si e ao outro, a imagem que eles se fazem de seu próprio lugar e do lugar do outro". No processo de produção do sentido importa a imagem que o locutor faz do lugar do outro (de si mesmo ou do referente) na interlocução.
}

INTERLETRAS, ISSN N 1807-1597. V. 9, Edição número 34. Outubro, 2021/ Março de 2022- p.

Dossiê: Estudos de indigenismo, negritude e miscigenação: o (des)cobrimento, colonização e o agora(?) . 
aponta Orlandi (2012), esse processo ocorre pela interpelação. O corpodiscurso encontrase, então, inscrito na história e significa.

Conforme Hashiguti (2009), em uma perspectiva discursiva, o corpo se desloca para o lugar da opacidade, porque, no discurso, ele é forma material que ganha sentido pelo olhar. Seguindo a perspectiva dos autores, o corpo negro enquanto materialidade discursiva significa diferentemente do corpo branco. Os atravessamentos históricos e ideológicos no corpo negro são outros, já que os sentidos provocados pelo olhar a este corpo são marcados por discriminação e desumanização desde o período da escravidão até os dias de hoje.

De acordo com Orlandi (2012, p. 93), o corpo do sujeito está ligado ao corpo social:

O corpo do sujeito é, nas condições sócio-históricas em que vivemos, parte do corpo social tal como ele está significando na história. Isto quer dizer, entre outras coisas que o sujeito relaciona-se com o seu corpo já atravessado por uma memória, pelo discurso social que o significa, pela maneira como ele se individualiza. No entanto, sempre há incompletude, a falha, o possível. E os sentidos, como tenho repetido, sempre podem ser outros.

Entendendo que o corpo do sujeito é parte de um corpo social e significa na história, o corpo negro tem uma significação outra em relação ao corpo branco, e essa significação é efeito de uma inscrição social e ideológica. Do corpo negro, por toda história de desumanização, escravidão e subserviência, emergem outros sentidos, que não os mesmos do corpo branco.

Não é por acaso que as grandes massas de população pobre e carcerária são compostas por negros. O sujeito negro traz consigo uma inevitável chaga, de um tratamento desumanizado, inclusive nos momentos pós-abolição, quando não houve políticas públicas para ampará-los, após anos de escravidão. Os negros libertos ficaram em situação de vulnerabilidade social, continuando, na maioria das vezes, em situações de servidão análogas à escravidão. A discursivização da negritude passa por um processo sócio-histórico-ideológico de dominação e subjugação da pessoa negra, o qual construiu os sentidos de marginalidade, desumanização e impureza reproduzidos pela ideologia dominante e, por conseguinte, presos ao imaginário de pessoa negra que circula na nossa formação social.

O corpo negro dentro de um corpo social se constitui por uma memória, entendida, nesta perspectiva, não como a memória biológica ou individual, mas, conforme aponta Pêcheux (2015, p. 44): “[...] nos sentidos entrecruzados da memória mítica, da memória social inscrita em práticas, e de memória construída do historiador". Nesse sentido, a memória construída/constituída sobre o negro é permeada por discursos discriminatórios e preconceituosos, os quais permitem a emergência de alguns sentidos que mantêm as relações de dominação vinculadas à raça. Essa memória, como afirma Orlandi (2005, p. 31), é compreendida como o interdiscurso, ou seja, o já-dito, que fala antes, alhures, independentemente. Conforme a autora, "é o que chamamos memória discursiva: o saber

INTERLETRAS, ISSN N $N^{\circ}$ 1807-1597. V. 9, Edição número 34. Outubro, 2021/ Março de 2022- p.

Dossiê: Estudos de indigenismo, negritude e miscigenação: o (des)cobrimento, colonização e o agora(?). 
discursivo que torna possível todo o dizer e que retorna sob a forma de pré-construído, o já-dito que está na base do dizível, sustentando cada tomada de palavra" (ORLANDI, 2005, p. 31).

Entende-se que essa memória em relação ao negro foi constituída no Brasil para mantêlo em um papel de marginalização e submissão, pois, como falamos anteriormente, as grandes massas de pobreza no Brasil, não por acaso, são negras. E a pobreza, por conseguinte, leva muitos negros a serem vistos como inferiores intelectual e socialmente. Ernst (2010, p. 182) aponta algumas consequências sobre a memória discursiva relativa ao negro:

\begin{abstract}
Traços dessas práticas, ligados à memória do dizer - o interdiscurso -, incidem, pois, no sujeito e em seu discurso e constituem-se em saberes ideologicamente engendrados, cujos sentidos, ao longo do tempo, cristalizaram elementos culturais de caráter pontual e estereotipado, relativos ao negro. A restrição operada através do destaque dado, por exemplo, a sua habilidade para a música, especificamente ao samba, e ao futebol, provocam o apagamento de elementos importantes de sua formação social originária e bloqueiam a possibilidade de construção de uma história emancipatória.
\end{abstract}

Conforme a autora, a memória discursiva opera de forma bastante intensa no que tange a um imaginário sobre o negro. Ao longo da história, fomos "ensinados" que um negro bem sucedido seria jogador de futebol ou pagodeiro, por exemplo, pois não teria habilidades intelectuais para ser um médico, um engenheiro, um professor, entre outras profissões consideradas de maior prestígio social. Tais estereótipos, conforme a autora, corroboram para um apagamento de elementos da formação social do negro, ou seja, o negro é simbolizado pelo outro de forma discriminatória social e intelectualmente, e mesmo que haja alteração em sua posição de classe, o negro permanece permeado por essa memória discursiva, que, infelizmente, no Brasil, continua o depreciando. Em outras palavras, a cultura e as subjetividades do negro acabam por ser extintas da memória, restando o preconceito e a discriminação.

Muitos argumentos ditos científicos existiram para legitimar a escravidão, apontando os negros como biologicamente inferiores aos brancos. Conforme Santos (2002, apud Pereira, 2010), pesquisas foram realizadas no século XVIII a fim de comprovar, por uma perspectiva eugenista, a inferioridade do negro em relação ao branco, o que funcionou na legitimação da escravidão, pois, sendo o negro então concebido como inferior ao branco, ele ocuparia um lugar de subserviência biologicamente determinado. Como disse Pereira (2010), esses dispositivos engenhosos e sagazes, revestidos de preconceitos e desumanização, embasaram a barbárie da escravidão e criaram uma teoria racial, justificada pela biologia, afirmando que a natureza criou alguns indivíduos para comandar e outros para obedecer - os negros.

Silva (2017) mostra que a ideia da existência de uma raça superior também foi legitimada no Brasil por um discurso acadêmico e científico. Pesquisadores defendiam a tese de que o negro era um ser inferior ao branco e, em função disso, o Brasil seria um país atrasado.

INTERLETRAS, ISSN N $N^{\circ}$ 1807-1597. V. 9, Edição número 34. Outubro, 2021/ Março de 2022- p.

Dossiê: Estudos de indigenismo, negritude e miscigenação: o (des)cobrimento, colonização e o agora(?) . 
A solução para esse suposto atraso seria a vinda dos europeus para o Brasil: as "populações avançadas da Europa".

Muitos discursos nos séculos XVIII e XIX corroboraram para o processo de inculcação do discurso racista no Brasil. O motivo de atraso social e econômico era atribuído ao negro, que seria um ser incapaz de trazer desenvolvimento para aquela terra, já que era um ser humano inferior e não gozava da sabedoria e da nobreza atribuídas ao branco europeu. Uma reflexão mais profunda acerca do desenvolvimento social e econômico do Brasil não parecia ser o foco nessas pesquisas, visto que atribuir o atraso aos negros escravizados era uma solução mais fácil e conveniente.

Orlandi (2017, p. 96) aponta o preconceito como uma forma de censura e, no caso do racismo, diz que,

O que está censurado, silenciado é que a cor é parte do processo de individuação do sujeito pelo Estado, e de tal modo que, pela divisão social de sujeitos e sentidos produzida pelo político, a cor negra é estigmatizada: "não é para ser negro". Isto fica silenciado em dizeres que falam que negro é "x" ou " $y$ ", ficando para ele o custo de ter de justificar se é " $x$ " ou " $y$ ", quando na realidade o processo é de censura mesmo, ou seja, há uma interdição em, pura e simplesmente, ser negro.

Conforme a autora, existe uma divisão social de sujeitos, e o sujeito negro está interditado. Nessa divisão instituída pelo Estado, o negro é estigmatizado. É feio ser negro, é um erro ser negro. Essa divisão social de sujeitos tem suas raízes desde o tempo da escravidão, quando o negro servia para obedecer ao branco, sendo apagada a sua humanidade e subjetividade. Esses efeitos da escravidão, discursivamente ativos na nossa formação social, remontam a diversos preconceitos a respeito do corpo negro, provocando, inclusive essa interdição.

Após essas breves colocações sobre o corpo (negro) e o racismo (articuladas a algumas questões discursivas), buscaremos refletir sobre como essas questões, vinculadas ao cinema, operam no funcionamento discursivo da obra cinematográfica $O \dot{O} P a i, O ́$.

\section{UM GESTO DE ANÁLISE}

Duas sequências discursivas de uma cena do filme $O$ Paí, Ó serão nosso corpus de análise ${ }^{3}$. Antes de iniciar o processo de descrição e de interpretação do corpus, vamos trazer alguns elementos referentes à trama da narrativa fílmica. Como foi dito anteriormente, a trama se passa no cortiço de Dona Joana, onde a maior parte das personagens vive. Roque (Lázaro Ramos) é um pintor de carrinhos utilizados por

\footnotetext{
${ }^{3}$ Modesto (2018) analisou o mesmo filme também pelo olhar da AD. Entretanto, o autor analisa as sequências discursivas com o foco na materialidade vocálica.
}

INTERLETRAS, ISSN N 1807-1597. V. 9, Edição número 34. Outubro, 2021/ Março de 2022- p.

Dossiê: Estudos de indigenismo, negritude e miscigenação: o (des)cobrimento, colonização e o agora(?) . 
moradores do Pelourinho para a venda de diversos produtos. Além de trabalhar com os carrinhos, Roque, que possui uma personalidade marcante, é um aspirante a cantor de Axé e tem grande destaque na trama, pois faz uma mediação do conflito entre Dona Joana e os demais condôminos.

Além de Roque, vivem no cortiço o motorista de táxi Reginaldo (Érico Brás), sua esposa Maria (Valdinéia Soriano), a travesti Yolanda (Lyu Arisson), que é amante de Reginaldo, Raimunda (Cássia Vale), uma mulher que costuma jogar búzios no cortiço, Neuzão (Tânia Tôko), uma mulher homossexual e proprietária de um bar no Pelourinho, sua sobrinha Rosa (Emanuelle Araújo), Carmen (Auristela Sá), uma moradora que realiza abortos clandestinos em seu apartamento, Psilene (Dira Paes), irmã de Carmen, recém-chegada da Europa, e a Baiana (Rejane Maia), que possui uma barraquinha de acarajé da qual todos são clientes.

Diversas tramas se desenvolvem ao longo do filme com essas personagens. Além dos moradores do cortiço, há também outras personagens, como Boca (Wagner Moura). A personagem apresenta um aspecto de malandragem e, ao longo do filme, fica subentendido que é envolvido com a venda de drogas. Boca terá uma relação comercial com Roque, pois contratará seus serviços para a produção de alguns carrinhos. O conflito entre as personagens se dá quando Boca vai buscar os carrinhos que encomendou a Roque e não possui a quantia em dinheiro para realizar o pagamento. Parte do diálogo referente a esse conflito constituirá o nosso corpus de análise.

Frisamos que o próprio nome do filme materializa um gesto de resistência. $O$ Paí, $O$ é uma abreviação no "baianês" de "Olhe para aí, olhe", o que pode ser entendido como: "Olhe para nós, olhe". Olhe para a Bahia, olhe para a negritude, olhe para o corpo negro enquanto discurso.

As SD escolhidas para desenvolvermos nosso gesto de análise demostram um forte embate de sentidos entre o negro e o branco, resgatando a questão do racismo de forma latente. Tal embate é protagonizado em uma cena do já mencionado filme pelas personagens Roque e Boca. Como já mencionado, a arte (neste trabalho representada pelo cinema) é um campo vasto para os estudos do discurso, pois reproduz nela diferentes discursos que podem trazer à tona questões sociais passíveis de reflexão e análise. Entendemos que determinadas manifestações de arte, como o cinema, por exemplo, podem representar situações da realidade vivida em uma determinada sociedade.

Na cena que escolhemos, Boca vai à oficina de Roque buscar a encomenda dos carrinhos que havia feito a ele. Os carrinhos produzidos na oficina de Roque são usados pelos meninos (vendedores ambulantes) que oferecem seus produtos no Pelourinho. Boca não possui a quantia combinada com Roque para realizar o pagamento e pede a extensão do prazo de pagamento. Como Roque realizou seu trabalho dentro do prazo combinado, não aceita a proposta de Boca, e proíbe a retirada dos carrinhos da oficina. Os dois, então, começam a discutir.

INTERLETRAS, ISSN $N^{o}$ 1807-1597. V. 9, Edição número 34. Outubro, 2021/ Março de 2022- p.

Dossiê: Estudos de indigenismo, negritude e miscigenação: o (des)cobrimento, colonização e o agora(?) . 
Nossa análise estará centrada no diálogo entre as personagens já mencionadas, sendo a fala de Boca a SD01, e a fala de Roque, a SD02. As sequências trazem a transcrição literal das falas do filme.

(SD01) Boca: [...] exemplo o que rapá, você é negro, você é negro, certo. Você é negro, você é negro, você é negro, você é negro, você é negro, você é negro, você é negro! Certo.

(SD02) Roque: Eu sou negro, eu sou negro, sim, mas por um acaso nego não tem olhos, Boca? Hein, nego não tem mão, não tem pau, não tem sentido, Boca? Hein? Não come da mesma comida? Não sofre das mesmas doenças, Boca? Hein? Não precisa dos mesmos remédios? Quando a gente sua, não sua o corpo, tal qual um branco, Boca? Hein? Quando vocês dão porrada na gente, a gente não sangra igual, meirmão? Hein? Quando vocês fazem graça, a gente não ri? Quando vocês dão tiro na gente, porra, a gente não morre também? Pois se a gente é igual em tudo, também nisso vamo ser, caralho!

$\mathrm{Na}$ discussão entre os dois ocorre um embate sobre racismo. Boca acredita que Roque tem que aceitar as suas condições por ser negro. $\mathrm{O}$ aspecto linguístico que nos parece mais relevante de ser abordado na SD01 trata-se da palavra negro. Quando Boca profere a palavra inúmeras vezes, ela parece ter um efeito pejorativo. Pensar sobre o funcionamento da memória discursiva no que tange ao negro requer uma volta ao passado, um passado de mais de 300 anos de escravidão no Brasil.

A barbárie à qual os negros foram submetidos deixou graves consequências na sociedade brasileira. Essa memória sobre o negro produz sentidos já naturalizados, referidos ao sujeito negro como inferior e subalternizado, e a personagem Boca reproduz esses sentidos que levam ao racismo, utilizando a palavra negro de modo a subestimar a personagem Roque. A memória sobre o negro é tão marcada que somente ao afirmar que Roque é negro os sentidos emergem através da repetição da palavra. Caso o período não tivesse sido repetido insistentemente pela personagem, o efeito de sentido produzido seria diferente. A cada vez que o período é repetido, com a palavra negro ocupando a posição do predicativo do sujeito da oração, os sentidos vinculados à negritude, os quais podemos afirmar que são oriundos de uma formação discursiva da branquitude, são atualizados. Dizer que a outra pessoa é negra, ou seja, dizer o óbvio, não se trata de um processo ingênuo. Nesse caso, dizer o óbvio serve para marcar a posição do sujeito negro na sociedade brasileira, uma posição subalterna à branca.

A repetição da palavra negro por tantas vezes caracteriza, na SD01, o que Ernst (2009, p. 04) chama de excesso ${ }^{4}$. O excesso concerne a uma estratégia discursiva que se caracteriza por aquilo que está demasiadamente presente no discurso. No caso da SD01, a

\footnotetext{
${ }^{4} \mathrm{O}$ excesso pode fazer referência tanto a elementos léxico-sintáticos, como aqui observado, quanto a elementos suprassegmentais, conforme observado em Modesto (2018). No presente trabalho, vamos nos deter na discussão sobre a repetição lexical.
}

INTERLETRAS, ISSN N 1807-1597. V. 9, Edição número 34. Outubro, 2021/ Março de 2022- p.

Dossiê: Estudos de indigenismo, negritude e miscigenação: o (des)cobrimento, colonização e o agora(?) . 
personagem Boca, através da repetição da palavra negro, busca, como aponta a autora, estabelecer provavelmente a relevância de saberes de uma determinada formação discursiva, a qual representa uma posição na luta de classes.

Desse modo, na conjuntura da SD01, o excesso da palavra negro configura a afirmação de uma FD racista, que pode ser entendida como a FD da branquitude, pois a personagem fala de um lugar no qual o branco possui hegemonia e tem a intenção de subjugar Roque apenas por ser negro. Apesar de a cena ser ambientada na cidade de Salvador, na Bahia, estado brasileiro com o maior número de habitantes negros, a supremacia branca parece imperar, uma vez que os negros sempre foram subjugados e assim devem seguir, segundo o enunciado de Boca. Quando Roque nega a vontade de Boca, a personagem de Wagner Moura busca colocar Roque na posição de subserviência à qual os negros foram e são submetidos até hoje.

O diálogo entre as duas personagens evoca a questão do racismo, algo negado desde o início da escravidão no Brasil. Nascimento (1978) aborda algumas questões do chamado conceito da "democracia racial", conceito erigido com base em especulações intelectuais e apoio das chamadas ciências históricas (NASCIMENTO, 1978, p. 41). Essa suposta democracia racial configuraria uma relação harmoniosa entre brancos e negros, subentendendo-se que estes teriam as mesmas oportunidades na vida, não importando as suas origens raciais.

É perceptível, na discussão entre Roque e Boca, uma ruptura desse discurso de democracia racial, quando o argumento de Boca, para conseguir o prazo de pagamento dos carrinhos, é a cor da pele de Roque. Um sujeito negro dentro da estrutura social na qual vivemos não poderia desobedecer a um branco em nenhuma circunstância. A ruptura está operando justamente neste ponto: Boca, através da repetição da palavra negro, busca subjugar Roque, salientando a sua dominância branca. Poderíamos pensar que, no Brasil, país tão miscigenado, esse discurso (da democracia racial) seria o discurso dominante. Porém, vemos, através do diálogo exibido na cena do filme, que este parece ser um discurso forjado, no qual a democracia racial trata-se de um mito, mito que reveste um racismo estrutural naturalizado na sociedade brasileira há muito tempo, parte da memória discursiva. Esse mito busca "suavizar" as consequências dos mais de 300 anos de regime escravagista, bem como a desassistência dada ao povo negro no período pós-abolição.

Após as considerações acerca do conceito de democracia racial em relação ao diálogo do filme, pensaremos na questão das condições de produção dos discursos presentes nas SD em questão. Conforme aponta Orlandi (2005) as condições de produção compreendem o sujeito e a situação e podem ser consideradas em sentido estrito, o que seria correspondente ao contexto imediato, e em sentido amplo, considerando o contexto social, histórico e ideológico.

Sobre as SD analisadas, no que tange às condições de produção estritas, temos dizeres que emergem de um filme contemporâneo, oriundo de uma guinada no cinema nacional

INTERLETRAS, ISSN N 1807-1597. V. 9, Edição número 34. Outubro, 2021/ Março de 2022- p.

Dossiê: Estudos de indigenismo, negritude e miscigenação: o (des)cobrimento, colonização e o agora(?) . 
ocorrida a partir dos anos $2000^{5}$. Com o aumento da produção cinematográfica nacional, em algumas obras, são retratados problemas oriundos da sociedade brasileira, como o racismo, por exemplo. Temos então, um filme contemporâneo, ambientado no estado da Bahia (estado com maior população negra do país), no Brasil e nos primeiros anos da primeira década dos anos 2000. Podemos entender que, por se tratar de um filme atual, seu texto, consequentemente, representa essa atualidade.

Temos, então, nos primeiros anos de 2000, uma sociedade na qual os negros são libertos, já há quase 120 anos. Como dissemos anteriormente, existe um conceito de democracia racial que parece ser dominante no Brasil, principalmente pensando em um contexto de pós-abolição. Diante dessas condições de produção estritas poderíamos pensar que um diálogo como o que estamos aqui analisando não ocorresse. Porém, ao pensar nas condições de produção amplas dos discursos produzidos na cena do filme, é possível compreender como processos discursivos anteriores operam na (re)produção do discurso racista. Como já dissemos anteriormente, o filme é ambientado no estado da Bahia, lugar no qual foi atribuído o efeito de origem à nação brasileira há pouco mais de 500 anos; foi na atual cidade de Porto Seguro que os colonizadores portugueses desembarcaram em 22 de abril de 1500 .

De acordo com Nascimento (1978), poucos anos depois, em 1530, os africanos, já sob coerção dos europeus, aparecem exercendo sua função de "força de trabalho" e, em 1535, o comércio de negros escravizados para o Brasil já estava devidamente organizado, tendendo a crescer rapidamente. Ainda conforme o autor, a primeira atividade significativa da colônia portuguesa no Brasil tratou-se de plantações de açúcar, atividade que se expandiu rapidamente, em especial na Bahia e em Pernambuco. No ano de 1587, somente no estado da Bahia, já havia 47 engenhos de açúcar, o que demonstra a velocidade com que essa indústria se expandiu explorando a força de trabalho dos africanos (NASCIMENTO, 1978). A subjugação dos negros no território brasileiro trouxe efeitos nos processos de produção de sentidos relacionados à branquitude e à negritude, os quais podem ser observados na forma como Boca se refere a Roque no diálogo observado.

Percebemos, através da busca das condições de produção amplas, ou seja, que envolvem o contexto sócio-histórico-ideológico, que o estado da Bahia (assim como o Brasil, de forma geral) foi construído e desenvolvido economicamente através da força do trabalho escravo dos negros africanos. A exploração da mão de obra negra trouxe desenvolvimento econômico para o Brasil e para Portugal, às custas de suor e sofrimento dos negros escravizados. Temos, então, no estado da Bahia, o início da colonização portuguesa, o início do Brasil e, por consequência, o início da barbárie da escravidão. Dando um salto para 1888, ano em que ocorreu a assinatura da Lei Áurea, Lei que "libertou" os negros do regime escravocrata, temos mais de 300 anos dessa violência dos colonizadores

\footnotetext{
${ }^{5}$ Fonte: <http://cinemaemcena.cartacapital.com.br/coluna/ler/764/nao-gosta-de-filme-nacional-entenda-ocinema-da-retomada $>$ Acesso em 14 de jan. de 2019.
}

INTERLETRAS, ISSN N 1807-1597. V. 9, Edição número 34. Outubro, 2021/ Março de 2022- p.

Dossiê: Estudos de indigenismo, negritude e miscigenação: o (des)cobrimento, colonização e o agora(?) . 
europeus e de seus condescendentes contra o povo negro. Além dos mais de 300 anos de escravidão, o Brasil foi o último país a abolir o regime de escravatura (NASCIMENTO, 1978).

Articulando este contexto sócio-histórico-ideológico à SD01, percebemos no funcionamento do discurso de Boca uma lógica escravocrata e colonizadora. Mesmo em um contexto contemporâneo, o discurso de Boca traz à tona todos os anos de dominância dos brancos sobre os negros e, mesmo após a liberdade dos negros, a ideologia branca prevalece. Como já apontamos antes, na SD01, Boca reitera que Roque é negro e não pode contrariar a sua vontade, afirmando algo que é óbvio muitas vezes. Pensando em um contexto de produção do discurso, são mais de 300 anos de escravidão dos negros no Brasil e pouco mais de 100 anos de uma suposta liberdade concedida ao negro. Existe um intervalo de mais de 400 anos para que o discurso racista e a lógica colonialista fossem desnaturalizados. Mesmo pertencendo à mesma classe, a dominação de raça se presentifica na análise aqui pautada.

Ao proceder nosso gesto de análise da SD01, percebemos que esse discurso não foi desnaturalizado; pelo contrário, é ainda reproduzido, entendendo aqui que o filme representa a questão do racismo no Brasil de forma explícita. Confrontamos novamente o discurso presente na SD01 ao conceito de democracia racial, a partir do qual brancos viveriam harmoniosamente com os negros.

$\mathrm{Na}$ SD02, o enunciado de Roque produz uma ruptura sobre a formação imaginária que Boca atribui a ele ou, em outras palavras, a formação imaginária que o branco atribui ao negro. Para Pêcheux (1997) os elementos que constituem o discurso - A e B - não se tratam da presença física de organismos humanos individuais, mas designam lugares determinados na estrutura de uma formação social, como, por exemplo, na esfera econômica, o chefe e o operário. $\mathrm{O}$ autor aponta que esses lugares são marcados por propriedades diferenciais determináveis. Pêcheux (1997, p. 82) traz a hipótese "de que esses lugares são representados nos processos discursivos em que são colocados em jogo".

Assim, o que vemos funcionando nos processos discursivos "é uma série de formações imaginárias que designam o lugar que A e B se atribuem cada um a si e ao outro, a imagem que eles se fazem de seu próprio lugar e do lugar do outro" (PÊCHEUX, 1997, p. 82). Reforçando a ideia do autor, Silva (2012, p. 22) diz que as imagens que os sujeitos atribuem a si, ao outro e ao assunto tratado são constituídas por "já-ditos" e "já-ouvidos". Dessa forma, buscando articular a questão das formações imaginárias às SD aqui analisadas, percebemos que a imagem que Boca atribui a Roque se constitui por "já-ditos" e "já-ouvidos" sobre o negro, como, por exemplo: "O negro nasceu para servir ao branco", "o negro não deve desobedecer à vontade do branco", "o negro é acostumado a suportar tudo o que vem dos brancos", "o negro não tem vontade própria", "o negro não possui autonomia para comandar uma situação", entre outros. Nesse sentido, a imagem que Boca atribui a Roque a partir do que já foi dito e já foi ouvido é a imagem do negro subserviente

INTERLETRAS, ISSN N $N^{\circ}$ 1807-1597. V. 9, Edição número 34. Outubro, 2021/ Março de 2022- p.

Dossiê: Estudos de indigenismo, negritude e miscigenação: o (des)cobrimento, colonização e o agora(?) . 
ao branco, oriunda da formação discursiva dominante, a qual reproduz saberes da branquitude. Boca atribui a si mesmo a imagem do branco em uma posição hegemônica, que, pela branquitude, está em relação de dominação com relação ao negro.

Roque rompe com o imaginário de inferioridade do negro quando confronta Boca na SD02. Buscando elementos linguísticos para pensar sobre essa ruptura, encontramos, no primeiro período da SD02, a conjunção adversativa mas: "Eu sou negro, eu sou negro sim, mas por um acaso nego não tem olhos, Boca?". A conjunção adversativa produz o sentido de oposição, constituindo um enunciado dividido (COURTINE, 2009), trazendo o discurso-outro no funcionamento daquilo que é dito, colocando posições diferentes em circulação na mesma formulação; na SD02, é a partir dessa conjunção que Roque começa a romper com a imagem de negro subserviente que Boca atribui a ele, trazendo argumentos sobre as semelhanças entre o corpo negro e o corpo branco, posicionando-se em relação com o discurso-outro evocado a partir do operador de contrajunção.

Apesar da ruptura provocada pelo discurso de Roque, o qual se posiciona de forma contrária a Boca quanto ao imaginário sobre negritude evocado pela repetição da palavra negro, sentidos estabilizados historicamente mostram que o corpo negro é diferente do corpo branco. O corpo negro, conforme já afirmado, foi e ainda é violentado de diversas formas, desde a escravidão até os dias de hoje: os efeitos dessa barbárie explicam muito sobre o genocídio real e simbólico do negro.

Assim, os sentidos que emergem sobre o corpo negro não são os mesmos do corpo branco. O corpo negro é marcado e, mesmo em um lugar socialmente engendrado, a personagem Roque rompe com o que se espera, a partir de uma posição dominante na nossa formação social, de um negro. Outro elemento linguístico que nos chama a atenção na SD02 é o advérbio "não". Roque se afirma como negro pela negação, expressando por diversas vezes o referido advérbio: "Eu sou negro, eu sou negro sim, mas por um acaso nego não tem olhos, Boca? Hein, nego não tem mão, não tem pau, não tem sentido, Boca?'. Tanto a negação quanto a conjunção adversativa trazem a presença do discurso-outro no enunciado, o que significa que a posição não-dominante se constitui, fundamentalmente, a partir da posição dominante, e isso é marcado linguisticamente.

A negação nos enunciados de Roque parece resgatar o processo de desumanização pelo qual os negros passaram. O negro como criatura desumanizada, então, parece não ter corpo, não ter sentidos, não ser gente, não ser humano. Dessa forma, deve suportar tudo que venha de um branco. Roque, através da negação, afirma que o negro tem, sim, um corpo, pois tem olhos, mãos e todos os sentidos que um branco tem. Roque, em seus enunciados, demonstra a força e a resistência de um povo que, mesmo escravizado e violentado pelos brancos, resiste.

INTERLETRAS, ISSN N 1807-1597. V. 9, Edição número 34. Outubro, 2021/ Março de 2022- p.

Dossiê: Estudos de indigenismo, negritude e miscigenação: o (des)cobrimento, colonização e o agora(?) . 
O embate racial se instaura no diálogo das personagens de um filme contemporâneo ambientado na Bahia, estado com maior população de negros no país ${ }^{6}$. Esse discurso racista presente no filme traz uma grande provocação para um país onde muitas pessoas afirmam não existir o racismo (existiria, assim, uma suposta democracia racial). O diálogo presente na cena do filme resgata uma memória (constituída de esquecimentos) sobre os negros que está naturalizada no Brasil por uma longa história de escravidão e preconceitos, cujas reflexões, apesar de estarmos legalmente livres há mais de cem anos, ainda se fazem necessárias.

\section{CONSIDERAÇÕES FINAIS}

As questões de raça e cor em um país diverso como o Brasil, cuja mescla da população se deu pelos negros escravizados, e grande parte da população é negra, em um primeiro momento, parecem não ser uma pauta relevante. Porém, a história dos negros no Brasil desde a escravidão mostra que, infelizmente, negros e brancos não são iguais. O povo negro carrega até hoje marcas da barbárie que foi a escravidão. Nesse sentido, o corpo negro significa de diferente forma, diferente do corpo branco.

Neste trabalho, buscamos refletir sobre o corpo negro enquanto discurso e como a memória no âmbito da Análise de Discurso opera nos processos de significação sobre o negro. Através de algumas sequências discursivas presentes no filme $O ́ P a i, O ́$, buscamos refletir sobre o racismo bem como sobre as suas implicações no corpo (negro). Com um breve resgate histórico sobre o negro no Brasil foi possível relacionar questões de racismo e preconceito à questão do corpo enquanto materialidade. Através da língua, em uma perspectiva discursiva, foi possível articular essas questões (de racismo e preconceito) ao corpo (negro).

Reflexões sobre raça e cor no Brasil, por inúmeros motivos, se fazem necessárias no âmbito da Análise de Discurso e em outros campos da ciência. Nossas reflexões não cessam neste trabalho, uma vez que se trata de uma pauta bastante ampla e suscetível de maiores considerações.

\section{REFERÊNCIAS}

COSTA, J. F. Da cor ao corpo: a violência do racismo. In: SOUSA, N. S. Torna-se negro. As vicissitudes da identidade do negro brasileiro em ascensão social. 2. ed. Rio de Janeiro: Edições Graal, 1983.p. 1-16.

\footnotetext{
${ }^{6}$ Fonte: <http://cinemaemcena.cartacapital.com.br/coluna/ler/764/nao-gosta-de-filme-nacional-entenda-ocinema-da-retomada> Acesso em 14 de jan. de 2019.
}

INTERLETRAS, ISSN N 1807-1597. V. 9, Edição número 34. Outubro, 2021/ Março de 2022- p.

Dossiê: Estudos de indigenismo, negritude e miscigenação: o (des)cobrimento, colonização e o agora(?) . 
COURTINE, J. J. Análise do Discurso político. O discurso comunista endereçado aos cristãos. São Carlos: EdUFSCar, 2009.

ERNST, A. A falta, o excesso e o estranhamento na constituição/interpretação do corpus discursivo. Disponível em: http://anaisdosead.com.br/4SEAD/SIMPOSIOS/AracyErnstPereira.pdf> . Acesso em: 15 ago. 2019.

GADET, F. Prefácio. [trad.] Eni Orlandi. In: GADET, F; HAK, T. (Orgs.) Por uma análise automática do discurso: uma introdução à obra de Michel Pêcheux. [trad] Bethania S. Mariani et al. $3^{\text {a }}$ ed. Campinas: Editora da Unicamp, 1997.

GARDENBERG, Monique; MEIRELLES, Márcio;.Ó Paí, ó [Filme-video]. Producao Guel Arraes, Augusto Casé, Maria Iunescu, Paula Lavigne. Direção de Monique Gardenberg. DVD, 96 minutos. Brasil, 2007.

HASHIGUTI, S. T. O corpo como materialidade do discurso. In: INDURSKY, F.; FERREIRA, M.C.L., MITTMANN, S. (Org.). O discurso na contemporaneidade. Materialidades e fronteiras. 1. ed. São Carlos: Clara Luz, 2009, p. 161-168.

MODESTO, R. Interpelação ideológica e tensão racial: Efeitos de um grito. Littera Online. Revista do Programa de Pós-Graduação da Universidade Federal do Maranhão, v 9, n 17, 2018, p. 124-145.

NASCIMENTO, A. O genocídio do negro brasileiro. Processo de um racismo mascarado. Rio de Janeiro: Paz e Terra, 1978.

ORLANDI, E. Análise de discurso. Princípios e procedimentos. 6. ed. Campinas: Pontes, 2005. 2012.

- Discurso em análise. Sujeito, sentido e ideologia. 2. ed. Campinas: Pontes,

. Eu, tu, ele. Discurso e real da história. 2. ed. Campinas: Pontes, 2017.

PÊCHEUX, M. Semântica e discurso. Uma crítica à afirmação do óbvio. 2 ed. Campinas: Unicamp, 1995.

. Análise Automática do Discurso. [trad.] Eni Puccinelli Orlandi e Greciely Costa. Campinas, SP: Pontes, 2019.

INTERLETRAS, ISSN N 1807-1597. V. 9, Edição número 34. Outubro, 2021/ Março de 2022- p.

Dossiê: Estudos de indigenismo, negritude e miscigenação: o (des)cobrimento, colonização e o agora(?) . 
PEREIRA, A. E. A escrita de si. Diferença racial e construção de subjetividades. In: TFOUNI, L.V. (Org.). Letramento, escrita e leitura. Questões contemporâneas. Campinas: Mercado de Letras, 2010, p. 181-196.

SILVA, J. M. da. Raízes do conservadorismo brasileiro. A abolição na imprensa e no imaginário social. 2. ed. Rio de Janeiro: Civilização Brasileira, 2017.

SOUSA, N. S. Torna-se negro. As vicissitudes da identidade do negro brasileiro em ascensão social. 2. ed. Rio de Janeiro: Edições Graal, 1983.

SOUZA, L. L. de. O Discurso encarnado: ou a passagem da carne ao corpo

discurso. Entremeios, Pouso Alegre, v. 1, n. 1, p. 1-9, 2010.

* Universidade Federal de Pelotas, Pelotas, Rio Grande do Sul, Brasil. E-mail: luisahidalgounipampa@gmail.com

** Universidade Federal do Rio Grande do Sul, Porto Alegre, Rio Grande do Sul, Brasil. E-mail: lucianavinhas@gmail.com 